\title{
Hypocalcaemia leading to supra ventricular tachycardia in a three- month old Sri Lankan infant with vitamin D deficient rickets: a case report
}

\author{
MP Fernando', PJ Perera'1, K Uyangoda ${ }^{2}$, TN Suriapperuma², OG Muthukumarana ${ }^{2}$ \\ Ceylon Medical Journal 2017; 62: 242-43 \\ DOI: http://doi.org/10.4038/cmj.v62i4.8576
}

\section{Introduction}

Supra ventricular tachycardia is is known to occur in infancy. However, only a single publication reports supra ventricular tachycardia occurring due to hypocalcaemia [1]. Hypocalcaemia during infancy can be due to many reasons. Vitamin D deficient rickets is one of them [2, 3]. There are only a few reports regarding symptomatic hypocalcaemia due to nutritional rickets. We could not find any reports of association between supra ventricular tachycardia and vitamin $\mathrm{D}$ deficient rickets.

Rickets is exclusively a childhood illness which occurs due to under-mineralization of the growth plates. Vitamin D deficiency is still a common, treatable cause of rickets which is often overlooked $[4,5]$. Despite being a tropical country with plenty of sunlight, nutritional rickets is not uncommon in Sri Lanka [5]. However, infants are protected due to maternal vitamin $\mathrm{D}$, which is transmitted to the baby via breast milk during the early part of infancy provided the mother has adequate D stores [2].

Though, hypocalcaemia is a known consequence of vitamin $\mathrm{D}$ deficiency, it is typically not severe enough to be life threatening [2,3]. We report a Sri Lankan infant of 3 months, who had two episodes of supra ventricular tachycardia due to severe hypocalcaemia, caused by vitamin D deficient rickets.

\section{Case report}

A three-month old baby boy, who was previously well, was admitted with excessive crying of few hours duration. He was the fifth child in the family and the mother had not taken calcium supplements during pregnancy. On admission, the heart rate was 280 beats per minute and the cardiac monitor showed narrow complex tachycardia without $\mathrm{p}$ waves which lead to a diagnosis of supra ventricular tachycardia. There were no clinical features to suggest congenital heart disease and the baby was thriving well. This episode of supra ventricular tachycardia was managed with vagal maneuvers until results of investigations were available.
After a few hours he had a second episode of supra ventricular tachycardia. After the laboratory reported low ionized calcium level of $1.2 \mathrm{mmol} / 1$ (normal range $2.2-2.7$ ) he was started on intravenous $10 \%$ calcium gluconate. Cardiac rhythm returned to sinus rhythm with a heart rate of 130 beats per minute.

He was investigated for hypocalcaemia. Ionized calcium levels were persistently low with low phosphate $1.26 \mathrm{mmol} / \mathrm{l}(1.45-2.16)$ and high alkaline phosphatase $1563 \mathrm{IU} / 1$ (145-420). X ray of the wrist showed classic features of rickets. Vitamin D (25-OH D) was 36.9 $\mathrm{nmol} / \mathrm{l}$ (deficient $<50$ ) and parathyroid hormone was $383.2 \mathrm{pg} / \mathrm{ml}$ (14-87). The mother's vitamin D level was $44 \mathrm{nmol} / \mathrm{l}$ (deficient $<50$ ). Venous blood gas, renal and liver functions were normal. 2D echocardiogram showed a small atrial septal defect which was haemodynamically insignificant.

During the initial period he was managed with intravenous calcium and calcitriol [1]. Ergocalciferol, stoss therapy 150,000 IU was given. Maintenance therapy was started with $400 \mathrm{IU} /$ day together with calcium and phosphate supplements which we planned to continue untill normalization of biochemistry. Mother was also started on vitamin D and calcium supplements.

\section{Discussion}

Rickets is the classical clinical manifestation of vitamin $\mathrm{D}$ deficiency and it can occur anytime during childhood [5]. However, the peak incidence is between 3 to 18 months. Breast fed babies are more vulnerable due to the low levels in breast milk $[2,3]$. Our patient presented at 3 months of age, probably due to the fact that the mother was deficient in vitamin $\mathrm{D}$ and he was on exclusive breast feeding $[2,3]$.

It is not typical to encounter extremely low calcium levels in vitamin D deficiency and arrhythmia is an unusual presentation. In our patient the serum calcium levels were very low at the time he developed supra 1Department of Paediatrics, Faculty of Medicine, University of Kelaniya, 2University Paediatric unit, Colombo North
Teaching Hospital, Ragama

Correspondence: MPF, e-mail: < meranthif@gmail.com>. Received 27th September 2017 and revised version accepted 11th November 2017.

This is an open-access article distributed under the terms of the Creative Commons Attribution License, which permits unrestricted use, distribution, and reproduction in any medium, provided the original author and source are credited. 
ventricular tachycardia and the cardiac rhythm became normal after correction of hypocalcaemia.

Though there are reports of supraventricular tachycardia associated with hypocalcaemia, there are no case reports of a similar presentation due to nutritional rickets [1]. There are also no reports in infants.

This case highlights that vitamin D deficiency can be life threatening due to hypocalcaemia associated supraventricular tachycardia. It is also noteworthy that vitamin $\mathrm{D}$ deficiency can occur in a community despite good health education and free vitamin supplementation programmes by the government. Hence, if an infant develops hypocalcaemia it is important to look for vitamin $\mathrm{D}$ deficiency in the infant as well as in the mother. Mothers who are vitamin D deficient, should be treated.

\section{Acknowledgements}

We would like to acknowledge Dr. B K T P Dayanath, Consultant Chemical Pathologist, Colombo North Teaching Hospital, Ragama for arranging 25-hydroxy vitamin D and PTH testing.

\section{Conflicts of interest}

Authors declare that there are no conflicts of interests.

\section{References}

1. Leibovitz A, Golic A, Brauman A, Gilboa Y. Supraventricular tachycardia due to hypocalcemia, Harefuah.1980;99(7):174-5

2. Vuletić B, Marković S, Igrutinović Z, Vladimir R, Rasković Z, Simović A. Case report of an infant with severe vitamin $\mathrm{D}$ deficiency rickets manifested as hypocalcemic seizures, Srp Arh Celok Lek 2016;144(1-2):90-93

3. Walter C, Muñoz-Santanach D, Marín Del Barrio S, Corrales Magín E, Pou Fernández J. Symptomatic hypocalcaemia due to nutritional rickets. A presentation of two cases; An Pediatr (Barc) 2010;72(5):343-6.

4. Kliegman, Robert, et al. Nelson Textbook of Pediatrics. Edition 20. Phialdelphia, PA: Elsevier, 2016.

5. Atapattu, N. Approach to a child presenting with rickets. Sri Lanka Journal of Child Health 2013;42(1), 40-44 